\title{
Prevalence of Multiple Sclerosis in First Nations People of Alberta
}

\author{
Lawrence W. Svenson, Sharon Warren, Kenneth G. Warren, Luanne M. Metz, \\ Scott B. Patten, Donald P. Schopflocher
}

\begin{abstract}
Background: Multiple Sclerosis (MS) is reported to be uncommon among North American aboriginals despite frequent intermarriage with people of European ancestry, but few population-based studies have been conducted. The purpose of this study was to determine the prevalence of MS among First Nations aboriginal people in Alberta, Canada compared to the general population. Methods: All hospital in-patient and physician fee-for-service records between 1994 and 2002 where a diagnosis of MS was mentioned were extracted from government health databases in the province of Alberta. First Nations people can be identified since the federal government (Health Canada) pays health care insurance premiums on their behalf. Multiple Sclerosis prevalence per 100,000 population for both First Nations people and the general population of Alberta were calculated for each year during this time span. Results: Among First Nations in Alberta, MS prevalence was 56.3 per 100,000 in 1994 and 99.9 per 100,000 in 2002, an increase of 43.6\%. In 2002 prevalence was 158.1 and 38.0 for females and males respectively, a female to male ratio of 4.2:1. Multiple Sclerosis prevalence among the general population of Alberta was 262.6 per 100,000 in 1994 and 335.0 per 100,000 in 2002 , an increase of $21.6 \%$. In 2002 prevalence was 481.5 and 187.5 for females and males respectively, a female to male ratio of $2.6: 1$. Peak prevalence for both First Nations and general population females in 2002 was age 50-59, also 50-59 for both First Nations and general population males. Conclusion: While MS prevalence in First Nations people is lower than in the general population of Alberta, it is not rare by worldwide standards.
\end{abstract}

RÉSUMÉ: Prévalence de la sclérose en plaques chez les Premières Nations de l'Alberta. Contexte : La sclérose en plaques (SEP) serait rare chez les autochtones nord-américains malgré des mariages interethniques fréquents, avec des individus dont les ancêtres étaient européens. Cependant il y a eu peu d'études de population sur ce sujet. Le but de cette étude était de déterminer la prévalence de la SEP chez les autochtones des Premières Nations de l'Alberta, au Canada, et de la comparer à celle de la population en général. Méthodes : Les données concernant les patients hospitalisés et les données de facturation des médecins entre 1994 et 2002 comportant un diagnostic de SEP ont été extraites des bases de données de soins de santé du gouvernement de la province d'Alberta. Les individus des Premières Nations peuvent être identifiés parce que le gouvernement fédéral (Santé Canada) paie les primes d'assurance santé en leur nom. La prévalence de la SEP par 100000 habitants pour les individus des Premières Nations et pour la population en général a été calculée annuellement. Résultats : Chez les Premières Nations de l'Alberta, la prévalence de la SEP était de 56,3 par 100 000 en 1994 et de 99,9 par 100000 en 2002, soit une augmentation de 43,6\%. La prévalence en 2002 était de 158,1 chez les femmes et de 38,0 chez les hommes, soit un ratio de 4,2:1. La prévalence de la SEP dans la population en général de l'Alberta était de 262,6 par 100 000 en 1994 et de 334,0 par 100000 en 2002, soit une augmentation de 21,6\%. La prévalence en 2002 était de 481,5 pour les femmes et de 187,5 pour les hommes, soit un ratio de 2,6 : 1. En 2002, la prévalence la plus élevée chez les femmes, tant chez les Premières Nations que dans la population en général a été observée chez les femmes de 50 à 59 ans, alors que chez les hommes la prévalence la plus élevée a été observée chez les hommes de 50 à 59 ans chez les Premières Nations et dans la population en général. Conclusion : En Alberta, la prévalence de la SEP chez les Premières Nations est plus faible que celle de la population en général. Cependant, cette maladie n'est pas rare par rapport aux standards mondiaux.

Can. J. Neurol. Sci. 2007; 34: 175-180

Anecdotal evidence suggests that multiple sclerosis (MS) is virtually non-existent among certain racial groups, including Australian aborigines, ${ }^{1}$ New Zealand Maoris ${ }^{2}$ and blacks in South Africa. ${ }^{3}$ It has also been suggested that MS is uncommon among North American aboriginals, ${ }^{4-6}$ despite frequent intermarriage with people of European ancestry. Systematic studies of the prevalence of MS in these groups has rarely been undertaken however, possibly because a supposed low rate is consistent with the observation that MS prevalence is generally lower among non-Caucasians than Caucasians worldwide. ${ }^{7}$ All medium to high risk areas throughout the world have predominantly Caucasian populations. In countries with both
Caucasian and non-Caucasian populations, such as the United States, MS prevalence is lower in all non-Caucasian groups. ${ }^{4}$

From Alberta Health and Wellness (LWS, DPS), Department of Public Health Sciences (LWS, DPS), Faculty of Rehabilitation Medicine (SW), Multiple Sclerosis Patient Care and Research Clinic (SW, KGW), Faculty of Nursing (DPS), University of Alberta, Edmonton; Department of Community Health Sciences (LWS, SBP, DPS), Department of Clinical Neurosciences and Hotchkiss Brain Institute (LMM),

Department of Psychiatry (SBP), University of Calgary, Calgary, Alberta, Canada. ReCEIVED July 26, 2006. ACCEPTED IN FINAL FORM JANUARY 21, 2007.

Reprint requests to: Sharon Warren, Faculty of Rehabilitation Medicine, Room 348 Corbett Hall, University of Alberta, Edmonton, Alberta, T6G 2G4, Canada. 
In 2001 Mirsattari et $\mathrm{al}^{8}$ published the first population-based study of MS in North American aboriginals. Mirsattari et $\mathrm{al}^{8}$ identified seven aboriginal Canadians with MS in the province of Manitoba, Canada for a period prevalence of 40.0 per 100,000 for the span of years from 1970 through 1996. The rate Mirsattari et $\mathrm{al}^{8}$ calculated for Manitoba aboriginals is considerably lower than the estimated MS prevalence rate in Canada at 240 per 100,000 population, and especially the Canadian Prairie Provinces at 340 per $100,000 .{ }^{9}$ However it is not low by worldwide standards. Traditionally countries or racial groups worldwide have been classified as low risk for MS if their prevalence is less than 4 per 100,000 population, medium risk if prevalence is from 4 to 29 , and high risk if prevalence is 30 or greater. ${ }^{10}$

The purpose of this study was to determine whether the MS prevalence rate among aboriginals in the province of Alberta would confirm the high prevalence of MS observed in Manitoba aboriginals and to provide additional information on the distribution of MS among Canadian aboriginals. The aboriginal people of Alberta are grouped into different cultural and linguistic groups from Manitoba. The Manitoba groups include Chipeweyan (Athapaskan) in the north and Cree (Algonkian) with some Saulteaux (Souian) in the south. On the other hand, groups in Alberta include Beaver, Sarci and Chipeweyan (Athapaskan) in the north and Blackfoot, Blood, Peigan, Gros Ventre and Cree (Algonkian) in the south.

\section{METHODS}

Under the Constitution Act of Canada, 1982, section 35, the term aboriginal refers to indigenous populations that occupied the country before European colonization (Indian and Inuit) and also includes Métis (typically Indian and French ancestry). This study specifically focuses on treaty registration status Indians, as did Mirsattari et al, ${ }^{8}$ but uses the term for Indian currently recommended by Indian and Northern Affairs Canada: that is, First Nations people.

\section{Sources of Data}

Data needed to calculate MS prevalence rates were extracted from the Central Stakeholder Registry (CSR), the Alberta Health Care Insurance Plan (AHCIP) database, hospital in-patient and physician fee-for-service databases maintained by the province of Alberta's Ministry of Health and Wellness.

The CSR includes all residents of Alberta eligible for coverage with the AHCIP. Registration with the AHCIP is mandatory for all residents of the province. First Nations aboriginals who hold treaty registration status under the Indian Act of Canada can be identified in the CSR because the federal government (Health Canada) pays health care insurance premiums on their behalf, assigning them an identifier unique from any other groups in the provincial databases. A treaty status First Nations person is one who is listed in the Indian Register, an official record maintained by the federal government. Eligibility criteria are complex and changing but in brief they encompass persons who are members of a band, or the direct descendants of a band member, who use or are entitled to use a reserve that has been set aside by treaty with various British and Canadian governments in the history of the country. Besides federal government definitions, bands can set their own membership criteria, including two parents of Indian ancestry, one parent, $50 \%$ Indian blood and various other definitions. ${ }^{11}$ The CSR also includes non-treaty registration status First Nations, Inuit and Métis, but there is no unique identifying code which can be used to separate out their data; consequently MS prevalence rates could not be calculated for these groups. The Registry excludes members of the military, Royal Canadian Mounted Police (RCMP) and federal prison inmates.

Each person in the CSR is assigned a unique lifetime personal identifier (personal health number) which is used to track individuals across information systems. Individuals who have not paid their health insurance premiums are still able to access services, so non-payment of premiums is believed to have minimal impact on a person's ability to receive care. Comparisons between the CSR and Alberta Census data confirm that the AHCIP databases include approximately $99 \%$ of the province's population. The exclusion of groups such as the military, RCMP and federal prison inmates might reduce MS prevalence rates, particularly among males who predominate in these groups. There might also be some difference in the size of rate reduction among First Nations and the general population based on their relative proportions in the military, RCMP or federal prisons.

The hospital in-patient database contains a record of hospitalizations, approximately 380,000 per year. As part of the database, as many as 16 diagnostic codes can be recorded per hospitalization. This database uses International Classification of Diseases (ICD-9-CM) coding at the 4 digit level. The physician fee-for-service database contains a record of all physician visits and can include up to three diagnostic codes per claim, also using the ICD-9-CM coding scheme at the 4 digit level. The diagnostic code does not impact the amount of physician payment which is driven by the procedure codes.

\section{Data Extraction Procedures}

For this study, all hospital in-patient and physician fee-forservice records from 1994 to 2002 where a diagnosis of MS (according to the ICD-9-CM, 340 for MS) was mentioned were extracted. The year 1994 was selected as a starting point for presentation of prevalence estimates because a new coding system was introduced in that year which made it possible to more accurately identify treaty registration status First Nations people than before. In addition, by this time, the in-migration of women who had lost treaty registration status through marriage which followed passage of Bill C-31, 1985 had largely ceased, ${ }^{11}$ so that it would not greatly impact on MS prevalence rates for female First Nations.

An individual was defined as a case if they had one or more hospitalizations for MS or two or more physician visits over the previous ten years, although in fact many cases exceeded the minimum criteria. These particular criteria were chosen to give good specificity at the expense of sensitivity, therefore erring on the side of increased false negatives in favour of few false positives. Physician diagnostic criteria for MS can vary and this information was not available in the databases.

Demographic information for identified MS cases was derived from the Central Stakeholder Registry, specifically age, gender and treaty registration status. Treaty registration status First Nations cases were identified in the CSR by the above 
mentioned code which indicated that Health Canada paid health care insurance premiums on their behalf. This would produce First Nations rates for Alberta analogous to Mirsattari et al's, ${ }^{8}$ which also specifically encompassed aboriginals of treaty registration status. Numerators for the prevalence rates were respectively: all treaty registration status First Nations and all persons in the general population (including treaty registration status First Nations) with MS. Denominators for the prevalence rates were respectively: all treaty registration status First Nations people and all members of the general population of Alberta (including treaty registration status First Nations) without MS. This approach to rate comparisons is not atypical of epidemiological methods. Considering the results reported for this study, it would have the effect of lowering the general population rates, that is, the differences between rates would be an underestimate.

Names of persons with MS were not tracked by either Alberta Health personnel who derived and aggregated the data nor released to any other researchers involved in the study, in accordance with ethics guidelines operating within the province. All data used in the study were non-identifiable.

\section{Data Analysis}

Annualized MS period prevalence rates per 100,000 population and $95 \%$ confidence intervals (CIs) were calculated for the total treaty registration status First Nations population and the general population of Alberta for each year from 1994 through 2002. Using the direct method (i.e. weighting a set of observed category-specific rates according to a standard distribution), Alberta MS prevalence rates were standardized to 1996 Canadian census population. The 1996 Canadian population was used since it was the most recent one available at the time. In addition to age-standardized rates, gender- and agespecific rates were also calculated. Logistic regression was used to determine the odds of treaty registration status First Nations people being diagnosed with MS as compared to members of the general population of Alberta.

\section{RESULTS}

Table 1 shows the age-standardized MS prevalence rates per 100,000 population and 95\% CIs for registered First Nations and the general population of Alberta, for each year from 1994 through 2002. Rates for First Nations were considerably lower than for the general population for each year during this time span. Differences were unlikely to occur by chance as judged by non-overlapping confidence intervals. The CIs for First Nations were much wider than for the Alberta population due to the small number of cases. The increase in MS prevalence among First Nations was greater than the increase among the Alberta population between 1994 and 2002, 43.6\% and 21.6\% respectively. However, First Nations remained significantly less likely to be classified as having MS according to this study's criteria than members of the general population (odds ratio = $0.32,95 \%$ CIs $=0.26,0.40$ ) in 2002 .

Table 2 shows prevalence rates for female and male First Nations and the general population of Alberta, plus the female to male ratios, for each year from 1994 through 2002. The rate for females was significantly higher than for males among both First
Table 1: MS Prevalence Rates per 100,000 Population and 95\% Confidence Intervals (CIs) for First Nations (FN) People and the General Population (GP) of Alberta, 1994 to 2002 (age-standardized to the 1996 Canadian population)

\begin{tabular}{|c|c|c|c|c|c|c|c|c|}
\hline \multirow{2}{*}{ Year } & \multicolumn{2}{|c|}{ Cases } & \multicolumn{2}{|c|}{ Population } & \multicolumn{2}{|c|}{ Prevalence Rate } & \multicolumn{2}{|c|}{$95 \%$ CIs } \\
\hline & FN & GP & FN & GP & FN & GP & FN & GP \\
\hline 1994 & 34 & 6.617 & 86,469 & $2,694,339$ & 56.3 & 262.6 & $+v-20.4$ & $+i-6.4$ \\
\hline 1995 & 37 & 7,046 & 87,442 & $2,713,375$ & 610 & 2744 & $+1-209$ & $+i-6.4$ \\
\hline 1996 & 45 & 7,472 & 91,134 & $2,741,189$ & 68.4 & 285,3 & $+1-213$ & $+1-6.5$ \\
\hline 1997 & 50 & 7,909 & 95,106 & $2,791,334$ & 720 & 293.7 & $+i-21,2$ & $+1-6.5$ \\
\hline 1998 & 59 & 8.402 & 99,097 & $2,852,932$ & 81.1 & 3029 & $+1-218$ & $+1-6.5$ \\
\hline 1999 & 69 & 8,938 & 103,524 & $2,923,639$ & 88.2 & 312.0 & $+1-221$ & $+1-6.5$ \\
\hline 2000 & 79 & 9.463 & 107,610 & $2,968,536$ & 97.6 & 3220 & $+1-22.7$ & $7 /-6,5$ \\
\hline 2001 & 86 & 9.973 & 111,249 & $3,022,891$ & 103.1 & 330.3 & $+1-230$ & $-7-6.5$ \\
\hline 2002 & 90 & 10.412 & 114,418 & $3,086,646$ & 99.9 & 3350 & $+1-215$ & $+1-6.5$ \\
\hline
\end{tabular}

Nations and the general population for each year during this time span, as assessed by non-overlapping confidence intervals. Again CIs for First Nations were much wider than for the general population due to the small number of cases. The percentage increase in First Nations females was greater $(51.6 \%)$ than in males (8.4\%) between 1994 and 2002, and the male rates seem to have fluctuated from year to year while the female rates have

\section{Table 2: Age-standardized MS Prevalence Rates per 100,000 Population and $95 \%$ Confidence Intervals (CIs) by Gender for First Nations (FN) People and the General Population (GP) of Alberta, plus Female to Male Ratios, 1994 to 2002}

\begin{tabular}{|c|c|c|c|c|c|c|}
\hline \multirow[t]{2}{*}{ Year } & \multicolumn{2}{|c|}{$\begin{array}{l}\text { Female Prevalence Rate } \\
(95 \% \text { Cls) }\end{array}$} & \multicolumn{2}{|c|}{$\begin{array}{l}\text { Male Prevalence Rate } \\
(95 \% \text { Cls) }\end{array}$} & \multicolumn{2}{|c|}{$\begin{array}{l}\text { Female to } \\
\text { Male Ratio }\end{array}$} \\
\hline & FN & GP & $\mathrm{FN}$ & GP & FN & GP \\
\hline 1994 & $76.6(+1-33.1)$ & & $34.8(+1-23.6)$ & $161.9(+1-7.2)$ & $2.2: 1$ & $2.2: 1$ \\
\hline 1995 & $852(+1-342)$ & $379.3(+1-10.6)$ & $35.1(+1-23.6)$ & $168.4(+1-7,3)$ & $2.4: 1$ & $23: 1$ \\
\hline 1996 & $1006(+1-356)$ & $3974(+1-10.7)$ & $33.0(+(-221)$ & $171.8(+\div-7.3)$ & 3.17 & 23.1 \\
\hline 1997 & & & $29.5(+1-19.9)$ & $173.6(+-7.2)$ & $3.7: 1$ & 2.4 .1 \\
\hline 1998 & $129.1(+i-38.7)$ & $427,5(+i-10,8)$ & $29.6(+/-19.1)$ & $177,0(+1-7,1)$ & $43 ; 1$ & $2,4: 1$ \\
\hline 1999 & $131.5(-(-38.1)$ & $442.5(+1-10.8)$ & $42.1(+7-21.4)$ & $180.6(+1-71)$ & $3.1: 1$ & $2.5: 1$ \\
\hline 2000 & $147.6(-1-39.7)$ & $4584(+/-109)$ & $452(+1-21.8)$ & $1847(+1-7.1)$ & $3.3: 1$ & $2.5: 1$ \\
\hline 2001 & $155,6(+1-40,1)$ & $4738(+1-110)$ & $477(+7-21.7)$ & $185.9(+1-7.0)$ & 331 & 2,$6 ; 1$ \\
\hline 2002 & $158.1(+(-38.3)$ & $481.5(+-10.9)$ & $38.00+(-18.5)$ & $187.5(+-6.9)$ & $42: 1$ & 2.601 \\
\hline
\end{tabular}


shown consistent increases. Similarly the percentage increase in MS among general population females was greater $(24.7 \%)$ than in males $(13.7 \%)$, although both female and male rates seem to have shown consistent increases. The female to male ratios were typically slightly higher among First Nations than the general population.

Figure 1 shows the age-specific prevalence rates per 100,000 for First Nations by gender in 2002, and Figure 2 shows the agespecific prevalence per 100,000 for the general population of Alberta by gender for the same year. Peak prevalence for female First Nations and females in the general population of Alberta was similar, at age 50-59. There were no MS cases in First Nations females beyond the age 60-69 category, while there were MS cases in general population females up to the age of 80 plus. Peak prevalence for male First Nations was the same as for males in the general population at 50-59. There were no MS cases in First Nations males beyond the 50-59 age category, while there were MS cases in general population males up to the age of 80 plus.

\section{Discussion}

Prevalence rates reported in this study were derived from information recorded in provincial databases. The validity of diagnoses such as MS included in government health databases has been questioned. In particular concerns have been expressed that possible as well as probable/definite cases are included, which could inflate resultant MS rates. However, prevalence for the general population derived from Alberta Health and Wellness data are similar to those derived by studies in which diagnosis was verified by examination ${ }^{12-14}$ and population self-report, ${ }^{9}$ supporting the accuracy of database information. In addition, a

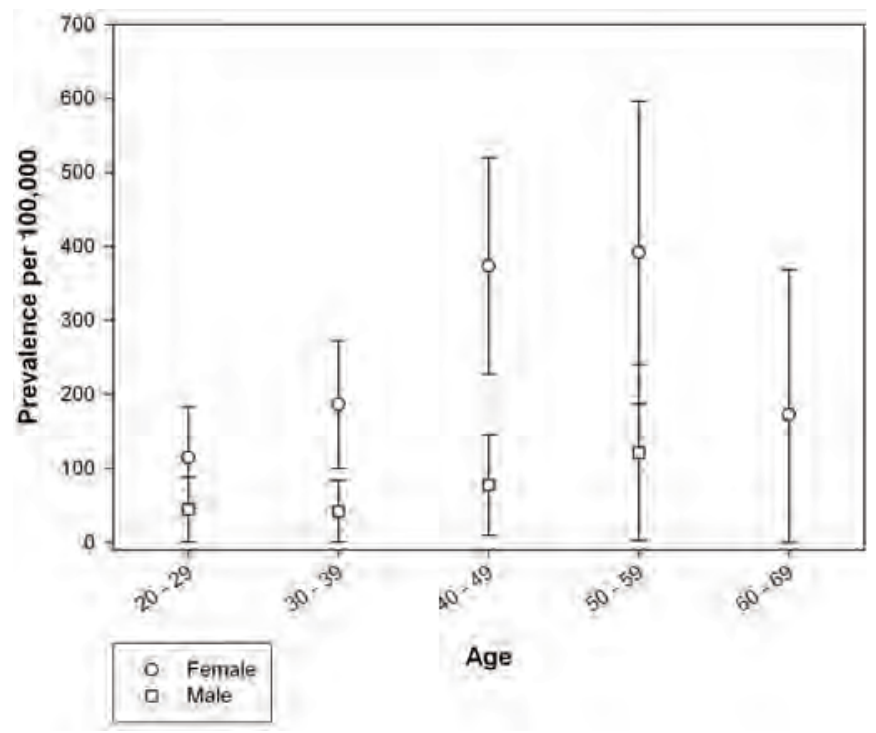

Figure 1: Age-specific MS prevalence rates per 100,000 population for First Nations people of Alberta, by gender, 2002 study addressing the validity of using government health databases in Nova Scotia for MS frequency estimates ${ }^{15}$ showed that the criteria of two physician visits (similar to this study) agreed well with diagnosis by a neurologist at the Dalhousie Multiple Sclerosis Research Unit in Halifax. The increased use of magnetic resonance imaging (MRI) may also have reduced the number of false positives since the 1990's. Because MS has been considered rare among aboriginals, any recorded case of MS in the database is likely to have been most thoroughly investigated for confirmation of diagnosis. On the other hand, since the data used in this study was analyzed retrospectively, some individuals would have been followed longer than others for possible changes in diagnosis, for example conversion to HTLV1, so that any issues related to changing diagnosis cannot be thoroughly examined.

The First Nations rates in this study do not necessarily apply to aboriginal people with no European ancestry. Six of the seven registered First Nations people with MS identified in Mirsattari et al's study ${ }^{8}$ reported one European ancestor each (one parent and five great-grandparents). Similar ancestry data was not available for First Nations people included in Alberta government health databases, so that it is impossible to say whether any of the cases had European ancestry or what degree of relationship they had if any. Mirsattari et al's group included six Cree and one Ojibway. Specific information on cultural or linguistic group was not available for Alberta because band membership might make individuals in the database identifiable, thus contravening privacy considerations. Further studies in Alberta involving direct contact with First Nations people who have MS would help to clarify band membership and ethnic admixture.

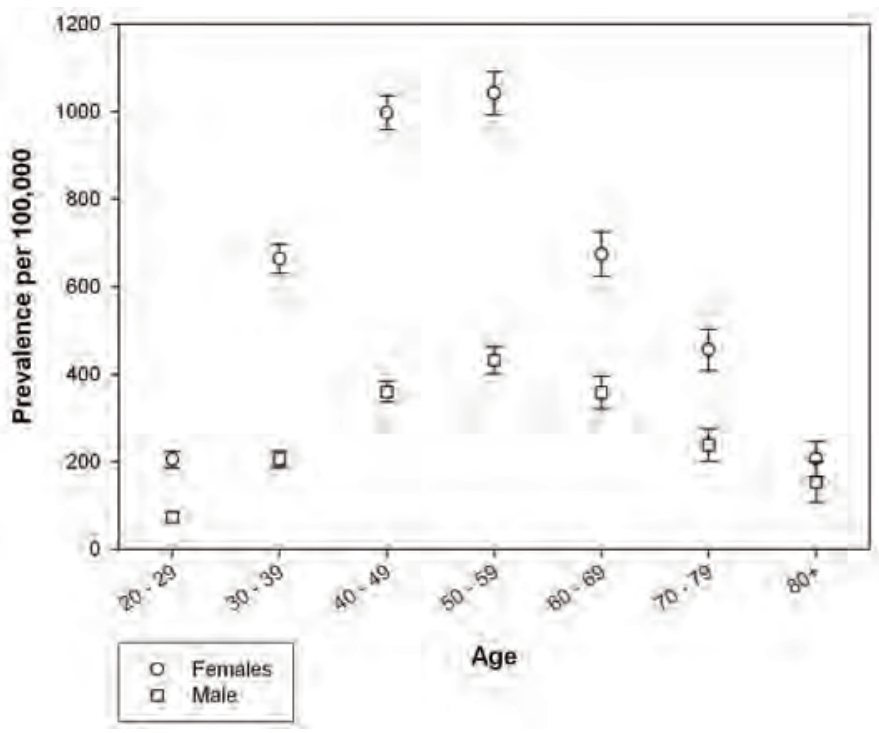

Figure 2: Age-specific MS prevalence rates per 100,000 population for general population of Alberta, by gender, 2002 
Mirsattari et al's ${ }^{8}$ study in Manitoba found a period prevalence rate of 40.0 per 100,000 for all registered First Nations and 56.6 per 100,000 for First Nations over ten years old for a time span from 1970 through 1996. The First Nations annualized period prevalence rates calculated for Alberta from 1994 through 2002 included all registered First Nations in the denominator, so are more comparable to the 40.0 per 100,000 Manitoba rate. The Alberta rates are higher than the Manitoba rate. This difference may be real or there are other possible explanations. The Manitoba period prevalence rate covers a wider time span, encompassing rates which were apparently lower in the 1970's and 1980's than 1990's since duration of disease was less than five years in five of the seven aboriginals identified with MS. Mirsattari et $\mathrm{al}^{8}$ may also have missed some cases since their data was based on registered treaty status aboriginals referred to two tertiary care hospitals in Winnipeg for neurological consultation. Aboriginals seen in the community may not always have been referred for confirmation of MS symptoms, especially during a time span when MS was thought to be rare among this group. Alternatively, the Alberta First Nations rates from 1997 onward may be higher because they are more recent and there has been a general trend for MS prevalence rates to increase over time among geographical regions worldwide and in both Caucasian and non-Caucasian groups. $^{7}$

Mirsattari et $\mathrm{al}^{8}$ identified four female and three male aboriginals who met the established criteria for an MS diagnosis, a ratio of 1.3:1. The Alberta First Nations female to male ratios are generally greater than this, with a high point at 4.2:1 in 2002. This difference could be real, reflect changing incidence patterns by gender or changing diagnostic practices over time, since the advent of MRI has facilitated confirmation of milder/relapsing remitting (RR) MS cases which are more common in females ${ }^{16}$ and could contribute to an increasing discrepancy in prevalence between females and males. However, only two of the five Manitoba aboriginals who had had MS for less than five years in Mirsattari et al's study were women, so the close female to male ratio has been maintained in recent years. The female to male ratios among First Nations and the general population of Alberta appear to be higher than the average reported worldwide at $1.4: 1,{ }^{7}$ while the $1970-1996$ Manitoba rate is more in line with this figure.

There is also an apparent difference in age-specific prevalence rates between Manitoba aboriginals observed in Mirsattari et al's study ${ }^{8}$ and Alberta First Nations. Among the female Manitoba aboriginals, two fell in the 20-29 age category, one in the 30-39 category and one in the 60-69 category; and among the males, two fell in the 20-29 age category and one in the 30-39 category. For those five Manitoba aboriginals with disease duration less than five years, two females and two males were in the 20-29 age category and one male in the 30-39 category. This is a generally younger distribution than in Alberta where peak age-specific prevalence was 50-59 for female and 50-59 for male First Nations people with MS, but might be due to missed cases in Manitoba during the 1970's and 1980's. The Alberta rates for both First Nations and the general population are more in line with age-specific prevalence rates worldwide which generally peaked in the mid- to late forties as of $1985^{17}$ and have recently shifted towards even older age peaks. ${ }^{7}$ The lack of Alberta First Nations cases in the oldest age categories compared to the general population may include several explanations. Among them would be a former lag in diagnosis of MS among First Nations, a general shorter life expectancy among First Nations people, less availability of or access to appropriate care, or a more severe form of MS particularly among First Nations males. Based on their study group, Mirsattari et al concluded that Manitoba aboriginals were at greater risk for an aggressive type of MS (according to elevated Expanded Disability Status Scores) than non-aboriginal MS controls, a type resembling neuromyelitis optica (NMO) which is more common in non-Caucasians and may sometimes be labeled as Devic's. There was no information available on disability status among Alberta First Nations from AHCIP data, nor information which would allow classification into recognized forms of MS including relapsing-remitting, secondary progressive, chronic progressive or NMO. Further information on the clinical picture of MS among First Nations through actual examination would be helpful in comparing the experience of aboriginal people in Manitoba and Alberta.

The apparently greater increase in MS annualized period prevalence rates from 1994 through 2002 among Alberta First Nations people compared to general population rates may be real or due to increasing awareness among physicians that MS may occur in this group, bolstered by the opportunity to confirm the diagnosis of MS using new techniques like MRI. Greater awareness among First Nations people that MS occurs in groups other than Caucasians and willingness to seek care for the disease might also play a role.

Greater increases in female than male MS incidence rates have been observed in some areas of the world in recent years, including Newfoundland, ${ }^{18}$ Finland, ${ }^{19}$ Norway, ${ }^{20,21}$ Alberta $^{22}$ and Canada in general. ${ }^{23}$ Sometimes this is attributed to an increase in the diagnosis of RR MS among females. However, KochHenriksen et $\mathrm{al}^{24}$ have recently suggested that it is due to a real increase in incidence, based on the observation that in Denmark there has been no change in onset age or in the percentage of RR MS cases being recorded. These researchers have speculated that a real increase in incidence might be related to increased exposure to some environmental risk factor, through occupational choices, lifestyle changes like increased smoking, or sexual practices including earlier entry into relationships and use of birth control. The greater increases in prevalence among both First Nations and general population females in Alberta may be due to a real increase in incidence, perhaps enhanced by females' apparently greater tendency to seek medical attention especially for milder symptoms. The greater increase in First Nations female MS prevalence may be further enhanced by increasing awareness of MS in this group, which would not be particularly changed for the general population during the same time span.

As in Manitoba, the prevalence of MS among First Nations people in Alberta cannot be considered low by worldwide standards. In fact it qualifies this group for high risk even if the more recently proposed rate of 60 per 100,000 high risk criterion is used. ${ }^{25}$ It is not clear whether prevalence was lower in the past, since no figures are currently available for previous years. 
A wide body of literature, including work from the Canadian Collaborative Project on Genetic Susceptibility to Multiple Sclerosis, suggests that MS is caused by an interaction between environmental and genetic risk factors. ${ }^{26}$ Caution should be observed when suggesting etiological hypotheses based on prevalence rather than incidence rates, especially in a disease like MS whose cause appears to have a long latency period. ${ }^{27}$ Nevertheless the high prevalence rate among Alberta First Nations compared to worldwide figures suggests that they are more frequently exposed to an environmental risk factor for MS possibly by virtue of living in Alberta where general population rates are very high compared to worldwide figures. The extent of First Nations' exposure to such a factor may be influenced by extent to which individuals have lived in/shared in life offreserve in the province. On the other hand, the fact that First Nations people in Alberta have a lower prevalence rate than the general population may suggest several possibilities, including lower exposure to an environmental risk factor, greater exposure to a protective environmental factor or lesser genetic predisposition despite increasing admixture. It may be noteworthy that MS continues to be rare or non-existent among other Canadian ethnic subgroups traditionally thought not to acquire MS, such as the Hutterites (W. Hader, personal communication, 2005) among whom admixture remains low, while MS among First Nations is apparently increasing.

Regardless, First Nations prevalence rates in Alberta (and Manitoba) suggest that Canadian First Nations people who present with symptoms of MS in any province should be investigated to confirm or discount the diagnosis. It may also be desirable to investigate the adequacy of services related to MS which are available to First Nations people.

\section{REFERENCES}

1. Hammond SR, McLeod JG, Millingen KS, Stewart-Wynne EG, English D, Holland JT, et al. The epidemiology of multiple sclerosis in 3 Australian cities: Perth, Newcastle and Hobart. Brain. 1988; 111: 1-25.

2. Skegg DCG, Corwin PA, Craven RS, Malloch JA, Pollock M. Occurrence of multiple sclerosis at the north and south of New Zealand. J Neurol Neurosurg Psychiat. 1987; 50: 134-9.

3. Kies BM. An epidemiological study of multiple sclerosis in Cape Town, South Africa. In: Chopra JS, Jagannathan K, Sawney IMS, editors. Advances in Neurology. Proceedings of the XIVth World Congress of Neurology, New Delhi, India. Amsterdam: Excerpta Medica; 278 (abstract 612B05), 1989.

4. Kurtzke JF, Beebe GW, Norman JE Jr. Epidemiology of multiple sclerosis in U.S. veterans: I. Race, sex and geographic distribution. Neurology. 1979; 29 (9 Pt 1): 1228-35.

5. Hader WJ, Feasby TE, Noseworthy JH, Rice GPA. Multiple sclerosis in Canadian native people. Neurology. 1985; 35 Suppl 1: 300 .

6. Oger J, Lai H. Demyelination and ethnicity: experience at the University of British Columbia Multiple Sclerosis Clinic with specific reference to HTLV-1-associated myelopathy in British Columbia natives. Ann Neurol. 1994; 36 Suppl: S22-4.
7. Warren S, Warren KG. Multiple Sclerosis. Geneva, Switzerland: World Health Organization, 2001, chapter 4.

8. Mirsattari SM, Johnston JB, McKenna R, Del Bigio MR, Orr P, Ross RT, et al. Aboriginals with multiple sclerosis: HLA types and predominance of neuromyelitis optica. Neurology. 2001; 56: 317-23.

9. Beck CA, Metz LM, Svenson LW, Patten SB. Regional variation of multiple sclerosis prevalence in Canada. Mult Scler. 2005; 11: 516-19.

10. Kurtzke JF. Epidemiologic contributions to multiple sclerosis: an overview. Neurology. 1980; 30: 61-79.

11. Furi M, Wherrett J. Indian status and band membership issues. Ottawa: Library of Parliament, Parliamentary Research Branch, 2003.

12. Warren S, Warren KG. Prevalence of multiple sclerosis in Barrhead County, Alberta, Canada. Can J Neurol Sci. 1992; 19: 72-5.

13. Warren S, Warren KG. Prevalence, incidence, and characteristics of multiple sclerosis in Westlock County, Alberta, Canada. Neurology. 1993; 43: 1760-3.

14. Klein G, Rose MS, Seland TP. The prevalence of multiple sclerosis in the Crowsnest Pass region of southern Alberta. Can J Neurol Sci. 1994; 21: 262-5.

15. Bhan V, Brown MG, Fisk JD, MacKinnon-Cameron D, Sketris IS, Murray TJ, et al. Incidence and prevalence of multiple sclerosis in Nova Scotia. Mult Scler. 2005; 11: 105.

16. Van Lambalgen R, Sanders EA, D'Amaro J. Sex distribution, age of onset and HLA profiles in two types of multiple sclerosis. A role for sex hormones and microbial infections in the development of autoimmunity? J Neurol Sci. 1986; 76: 13-21.

17. Acheson ED. The epidemiology of multiple sclerosis: the pattern of the disease. In: Matthews WB, editor. McAlpine's multiple sclerosis. Edinburgh: Churchill Livingstone; 1985.

18. Sloka JS, Pryse-Phillips WE, Stefanelli M. Incidence and prevalence of multiple sclerosis in Newfoundland and Labrador. Can J Neurol Sci. 2005; 32: 37-42.

19. Kinnunen E. Multiple sclerosis in Finland: evidence of increasing frequency and uneven geographic distribution. Neurology. 1984; 34: 457-61.

20. Gronning M, Riise T, Kvale G, Nyland H, Larsen JP, Aarli, JA. Incidence of multiple sclerosis in Hordaland, western Norway: a fluctuating pattern. Neuroepidemiology. 1991; 10: 53-61.

21. Gronning M, Mellgren SI. Multiple sclerosis in the two northernmost counties of Norway. Acta Neurol Scand. 1985; 72: 321-7.

22. Warren S, Svenson LW, Warren KG. Relative contribution of incidence and duration to increasing prevalence of multiple sclerosis in Alberta, Canada. Mult Scler. 2005; 11: 105.

23. Orton S-M, Herrera BM, Yee IM, Valdar W, Ramagopalan SV, Sadovnick AD, et al. Sex ratio of multiple sclerosis in Canada: a longitudinal study. Lancet Neurol. 2006; 5: 932-6.

24. Koch-Henriksen N, Stenager E, Bronnum-Hansen H, Flachs EM. Increasing incidence of multiple sclerosis in Danish women. Mult Scler. 2006; 12: 228.

25. Lauer K. The risk of multiple sclerosis in the U.S.A. in relation to sociogeographic features: a factor-analytic study. J Clin Epidemiol. 1994; 47: 43-8.

26. Sadovnick AD, Ebers GC. Epidemiology of multiple sclerosis: a critical overview. Can J Neurol Sci. 1993; 20: 17-29.

27. Kurtzke JF. Migration and latency in multiple sclerosis. In: Field EJ, et al, editors. Multiple sclerosis: Progress in Research. Amsterdam: North Holland; 1972. 